\title{
Polymer Drilling Fluid with Micron-Grade Cenosphere for Deep Coal Seam
}

\author{
Peng Xu, ${ }^{1}$ Han-qiao Xiong, ${ }^{1}$ Xiao-lin Pu, ${ }^{1}$ Ju-quan Liu, ${ }^{2}$ and Xing Liu ${ }^{1}$ \\ ${ }^{1}$ State Key Laboratory of Oil and Gas Reservoir Geology and Exploitation, Southwest Petroleum University, Chengdu, \\ Sichuan 610500, China \\ ${ }^{2}$ Karamay Vocational and Technical College, Karamay, Xinjiang 833600, China
}

Correspondence should be addressed to Peng Xu; cdxupeng@126.com

Received 8 March 2015; Accepted 16 August 2015

Academic Editor: Mariapaola Parisi

Copyright (C) 2015 Peng Xu et al. This is an open access article distributed under the Creative Commons Attribution License, which permits unrestricted use, distribution, and reproduction in any medium, provided the original work is properly cited.

\begin{abstract}
Traditional shallow coal seam uses clean water, solid-free system, and foam system as drilling fluid, while they are not suitable for deep coal seam drilling due to mismatching density, insufficient bearing capacity, and poor reservoir protection effect. According to the existing problems of drilling fluid, micron-grade cenosphere with high bearing capacity and ultralow true density is selected as density regulator; it, together with polymer "XC + CMC" and some other auxiliary agents, is jointly used to build micron-grade polymer drilling fluid with cenosphere which is suitable for deep coal seam. Basic performance test shows that the drilling fluid has good rheological property, low filtration loss, good density adjustability, shear thinning, and thixotropy; besides, drilling fluid flow is in line with the power law rheological model. Compared with traditional drilling fluid, dispersion stability basically does not change within $26 \mathrm{~h}$; settlement stability evaluated with two methods only shows a small amount of change; permeability recovery rate evaluated with Qinshui Basin deep coal seam core exceeds $80 \%$. Polymer drilling fluid with cenosphere provides a new thought to solve the problem of drilling fluid density and pressure for deep coal seam drilling and also effectively improves the performance of reservoir protection ability.
\end{abstract}

\section{Introduction}

Coal-bed methane (CBM) resource is rich in China, geological resource of deep coal seam has 22.54 trillion squares in $1000-2000 \mathrm{~m}$, and deep coal seam is an important direction of coal-bed methane exploration and development [1]. The use of drilling fluid is particularly important for efficient development of coal-bed methane; it is also a hot research topic in the field of coal-bed methane drilling engineering $[2,3]$. Compared with shallow coal seam, deep coal seam has characteristics of low permeability, low saturation, high ground stress, and fracture structure development [4]; it could not form a stable production capacity in the development process. Therefore, the drilling fluid used in coal-bed methane wells should improve the ability of drilling deep coal seam. Conventional drilling fluids are "clear water + a small amount of $\mathrm{KCl}$ " or low solid polymer system [5-7], which are suitable for shallow coal seam. But conventional clear water or low solid polymer system easily causes collapse and fluid loss in deep coal seam. Even if there are no engineering accidents, conventional drilling fluids would cause great damage to coal-bed methane reservoir, which would make extremely low production of coal-bed methane become lower, even without gas $[8,9]$.

At present, engineers often use solid-free polymer system and foam system to solve the drilling problem of deep coal seam wells [10-12]. However solid-free polymer system has great rheological properties and the ability of carrying cuttings, but the density of solid-free polymer system could not match the formation pressure coefficient; this would cause complex accidents in the process of drilling. At the same time foam system can solve the problems in deep coal seam, but the foam stability is poor, the half-life of foam is fairly short, and this disadvantage also brings many problems in the process of drilling. To sum up, the drilling fluids which are used in deep coal seam still have a number of shortcomings 
and need improvement and innovation. To solve the problem, the research chose micron-grade cenosphere to adjust density and improved the ability of compressive strength.

The drilling fluid based on cenosphere began to attract the worldwide attention in the 1990s. It was used to solve the problem of drilling fluid density adjustment. However, cenosphere, as the density regulator, is mainly used in drilling fluid and solid slurry operated by oil and gas, and it does not involve the ultralow density stratum of coal seam. In very early period, cenosphere had been used as density reducing agent. In the 20th century, the former Soviet Union tried to use cenosphere in drilling fluid as density reducing agent and leakproof agent [13]. In 1996, Mobil Oil Company successfully drilled two wells by using 10 20\% of cenosphere (21 Mpa of compressive strength, $0.8 \mathrm{~kg} / \mathrm{m}^{3}$ of density) low density drilling fluid $[14,15]$. Low density oil-base drilling fluid with cenosphere also has been successfully used in the United States and Russia [16]. Drilling fluid with cenosphere is successfully applied in Guangan 002-H1 Well in Sichuan basin, which had good performance of filtration loss and could be reused [17]. In 2007, underbalanced drilling was realized in Well DP3 in Daniudi Gas Field by using drilling fluid with cenosphere, and technical challenges such as bringing rock debits at horizontal section, borehole wall stability, and reservoir protection are successfully solved [18]. In 2010, Shenyang Number 289 Well used the drilling fluid with cenosphere; its daily yield increased $40.7 \mathrm{t}$ to $74.6 \mathrm{t}$ and the maintenance cost was low [19].

At present, there has been no case of the application of drilling fluid with cenosphere in coal-bed gas drilling, but the successful application in oil and gas shows that drilling fluid with cenosphere is a new way of thinking to solve the current problem for the coal seam with low pressure coefficient, since it can solve the ordinary water-based density adjustment problems and pressure-bearing of bubble type of drilling fluid and have good reservoir protection effect.

\section{Establishment of Drilling Fluid System}

2.1. Choice of System. From the analysis of introduction, solid-free polymer system has great rheological properties and foam system could be adjusted to match the formation pressure coefficient, so the research integrates the advantages of both to form a new system, and polymer system with micron-grade cenosphere could meet the requirements.

2.2. Micron-Grade Cenosphere. Micron-grade cenosphere is a super lightweight inorganic nonmetallic material which has been newly developed in recent years, it has high performance and a wide range of use, and it also has characteristics of light weight, large volume, low thermal conductivity, high compressive strength, and good rheological properties. True density of micron-grade cenosphere is ranging from 0.15 to $0.6 \mathrm{~g} / \mathrm{cm}^{3}$, its particle size is between 2 and $120 \mu \mathrm{m}$, and the biggest compressive strength can reach 10000 psi. Microngrade cenosphere is widely used in cement slurry but rarely used in drilling fluid.

Micron-grade cenosphere will not only reduce the density of solid-free polymer drilling fluid, but also solve the problem

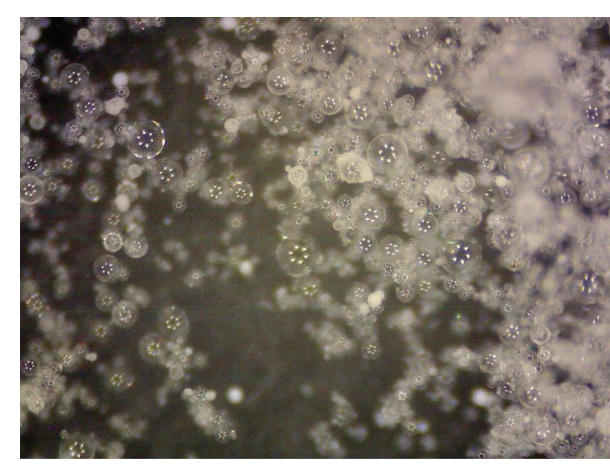

Figure 1: Micron-grade cenosphere which has been magnified 200 times.

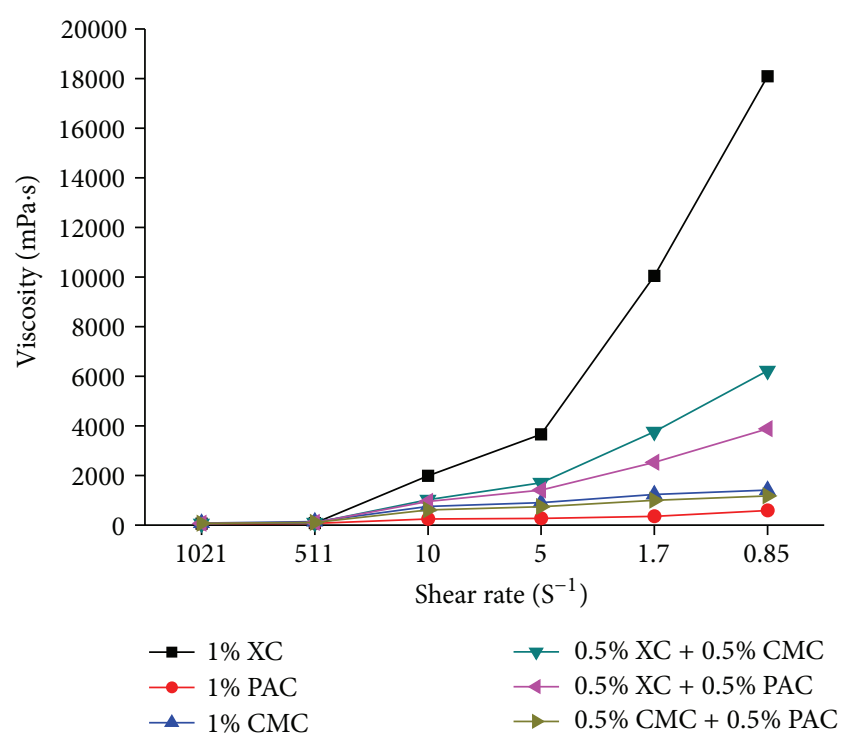

FIGURE 2: The apparent viscosity under different shear rate.

of compressive strength of foam system. Figure 1 shows the form of micron-grade cenosphere.

2.3. Choice of Tackifier. Tackifier is used to improve the system viscosity, adjust flow pattern, reduce fluid loss, and adjust the salt resistance and calcium resistance of fluid system. Frequent tackifiers have xanthan gum (XC), polyanionic cellulose (PAC), and carboxymethylcellulose sodium (CMC); these also have the effect of reducing filtration.

Laboratory experiments evaluated the rheology of XC, PAC (high viscosity), and CMC (high viscosity) under the same conditions with atmospheric rheometer (Grace 3600) and evaluated the rheology of compositional tackifier; the experiment results are shown in Table 1 and Figure 2.

Table 1 and Figure 2 show that the viscosity is similar under the shear rate of $1021 \mathrm{~S}^{-1}$, but with the decline of the shear rate, the viscosity continues to rise, and particularly XC rises fastest. This fully shows XC has good shear thinning behavior, and drilling fluid containing XC has the minimum invasion rate and depth in reservoir porous media, which is most beneficial to reservoir protection, so the research 
TABLE 1: The viscosity under different rotational speed.

\begin{tabular}{|c|c|c|c|c|c|c|c|}
\hline \multirow[b]{2}{*}{ Speed/Rpm } & \multirow[b]{2}{*}{ Shear rate $/ \mathrm{S}^{-1}$} & \multicolumn{6}{|c|}{ Viscosity/cP } \\
\hline & & $1 \% \mathrm{XC}$ & $1 \% \mathrm{CMC}$ & $1 \%$ PAC & $\begin{array}{l}0.5 \% \mathrm{XC}+ \\
0.5 \% \mathrm{CMC}\end{array}$ & $\begin{array}{c}0.5 \% \mathrm{XC}+ \\
0.5 \% \mathrm{PAC}\end{array}$ & $\begin{array}{c}0.5 \% \mathrm{CMC}+ \\
0.5 \% \mathrm{PAC}\end{array}$ \\
\hline 600 & 1021 & 56.7 & 49.8 & 88.0 & 58.0 & 66.1 & 68.6 \\
\hline 300 & 511 & 88.1 & 72.7 & 135.9 & 90.1 & 103.4 & 108.7 \\
\hline 6 & 10 & 1987.5 & 244.8 & 753.9 & 1018.2 & 949.7 & 616.8 \\
\hline 3 & 5 & 3661.7 & 274.1 & 900.7 & 1703.6 & 1409.9 & 744.1 \\
\hline 1 & 1.7 & 10045.2 & 352.5 & 1233.6 & 3759.6 & 2526.0 & 998.7 \\
\hline 0.5 & 0.85 & 18093.1 & 587.0 & 1409.9 & 6226.9 & 3877.1 & 1174.9 \\
\hline
\end{tabular}

TABLE 2: Basic performance test of drilling fluid.

\begin{tabular}{|c|c|c|c|c|c|c|}
\hline Density $/ \mathrm{g} \cdot \mathrm{cm}^{-3}$ & $\begin{array}{c}\text { Hours of } \\
\text { aging at } \\
100^{\circ} \mathrm{C}\end{array}$ & $\begin{array}{c}\text { Apparent } \\
\text { viscosity/cP }\end{array}$ & Plastic viscosity/cP & Yield point/Pa & Gel strength $/ \mathrm{Pa}$ & Filter loss (API)/mL \\
\hline \multirow{2}{*}{0.93} & 0 & 63 & 16 & 24.02 & 1.00 & \multirow{2}{*}{3.6} \\
\hline & 16 & 43 & 16 & 13.80 & 1.48 & \\
\hline \multirow{2}{*}{0.86} & 0 & 83 & 27 & 28.62 & 0.86 & \multirow{2}{*}{2.8} \\
\hline & 16 & 70 & 41 & 14.82 & 0.58 & \\
\hline \multirow{2}{*}{0.75} & 0 & 122 & 38 & 42.67 & 0.93 & \multirow{2}{*}{2.4} \\
\hline & 16 & 99 & 29 & 35.77 & 0.95 & \\
\hline
\end{tabular}

uses XC as a tackifier. However, drilling fluid needs good shear thinning behavior and thixotropy, and if the drilling engineering needs to stop the pump, the gel strength should increase to a certain value quickly, and this gel is beneficial to carry cuttings, and not to cause pump pressure too high, drilling fluid also needs low fluid loss, so the research chooses $\mathrm{XC}$ and another tackifier to form a compound tackifier. The results of Table 1 and Figure 2 show that " $0.5 \% \mathrm{XC}+0.5 \%$ CMC" has good shear thinning behavior and thixotropy; it meets the requirement of drilling fluid.

\subsection{Establishment of System. The structure of deep coal seam} is complex, formation is easy to show the damage of blocking and water locking caused by drilling fluid invasion, and the research joins ultrafine calcium carbonate, fiber, and waterproof lock agent to protect reservoir. The research also adds corrosion inhibitor to reduce the corrosion of drilling fluid in the process of drilling and adds antifoaming agent to reduce effect of foam in drilling fluid. After optimization and evaluation of several of additives by laboratory experiments, the research ultimately forms a complete formula: water + micron-grade cenosphere $+0.4 \sim 0.6 \% \mathrm{XC}+0.4 \sim 0.6 \% \mathrm{CMC}$ $+0.3 \sim 0.5 \%$ SATRO $+0.02 \sim 0.05 \%$ antifoaming agent $+0.5 \sim$ $1.5 \%$ QS-2 + 0.2 0.5\% fiber + others. Laboratory experiments evaluated drilling fluid with different density; the experiment results are shown in Table 2.

Table 2 shows the upper limiting conditions when drilling fluid with cenosphere is used in CBM wells; the filtration loss of drilling fluid after aging for $16 \mathrm{~h}$ at $100^{\circ} \mathrm{C}$ is evaluated. The experimental results show that under the API filtration loss of drilling fluid with different densities is always less than $5 \mathrm{~mL}$ and can meet the needs of engineering. At the same time, as

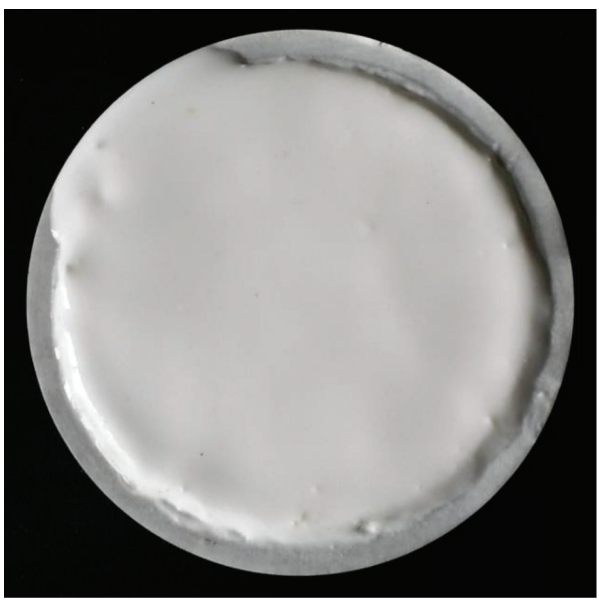

FIgURE 3: Mud cake filtration test forms when drilling fluid density is $0.93 \mathrm{~g} \cdot \mathrm{cm}^{-3}$.

the density decreases, filtration loss also decreases, because the temporary plugging particles added to the drilling fluid can have very small defiltration loss effect; besides, the wide particle size distribution (cenosphere diameter is $2-120 \mu \mathrm{m}$ ) also has the effect of blocking pore and further reduces filtration loss. As shown in Figure 3 mud cake when drilling fluid density is $0.93 \mathrm{~g} \cdot \mathrm{cm}^{-3}$, the situation of the mud cake is relatively good and the water loss wall building performance of drilling fluid is good.

Table 2 and Figure 3 show overall performance of drilling fluid is good, and the drilling fluid has strong temperature resistance, good rheological properties, and low flow loss. 


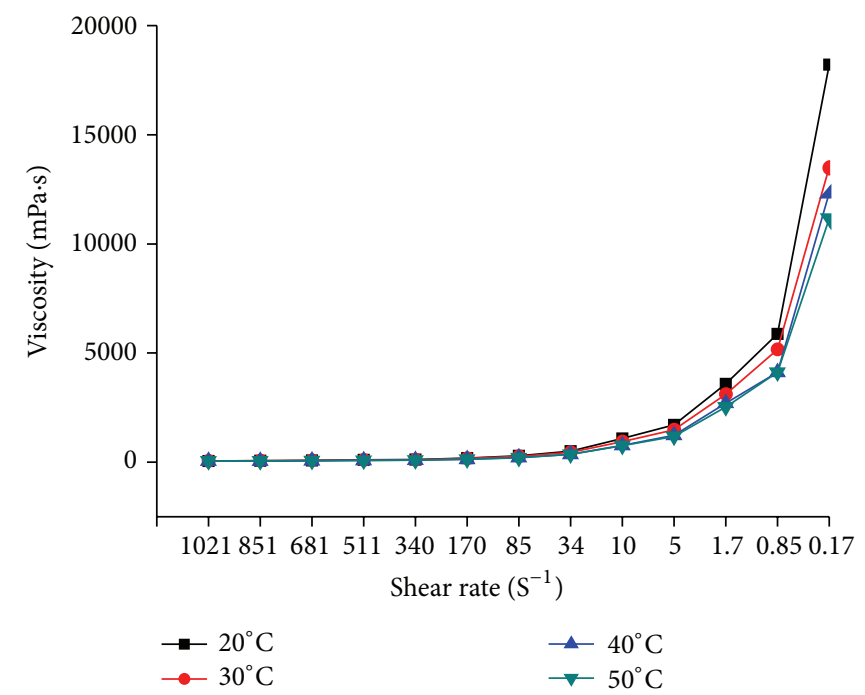

Figure 4: Rheological property under the same temperature and different shear.

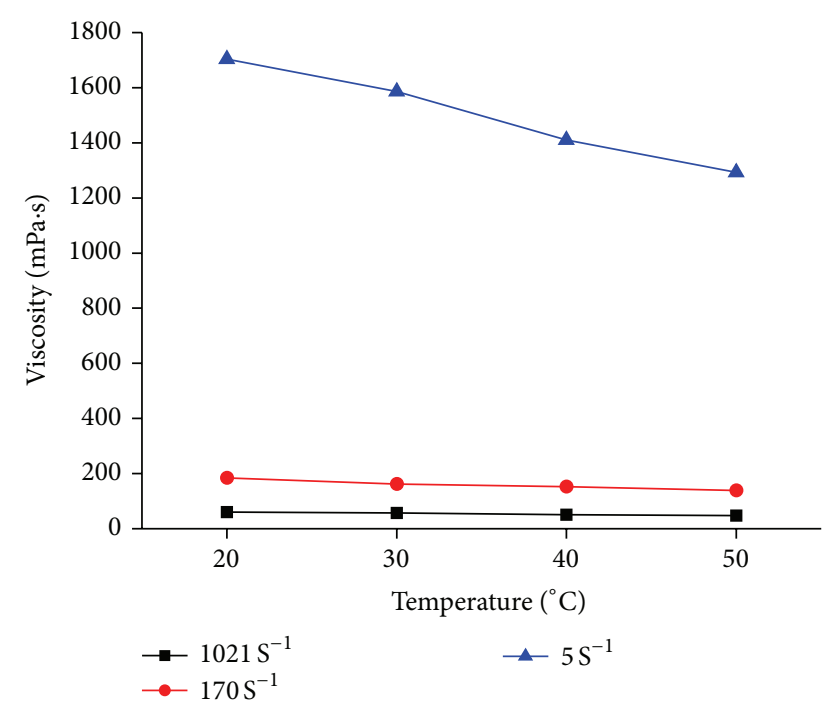

FIGURE 5: Rheological property under different temperature and the same shear rate.

\section{Results and Discussion}

Drilling fluid for deep coal-bed methane wells requires good system stability and ability of reservoir protection. The research evaluated the rheology properties under different temperature and different shear rate, dispersion stability, sedimentation stability, particle size distribution of drilling fluid, and ability of reservoir protection.

3.1. Rheology Evaluation under Different Temperature and Different Shear Rate. Laboratory experiments evaluated the rheology properties under different temperature and different shear rate with atmospheric rheometer (Grace 3600); the experiment results are shown in Figures 4 and 5.

Figure 4 shows the rheology properties under the same temperature and different shear rate; with the decline of the

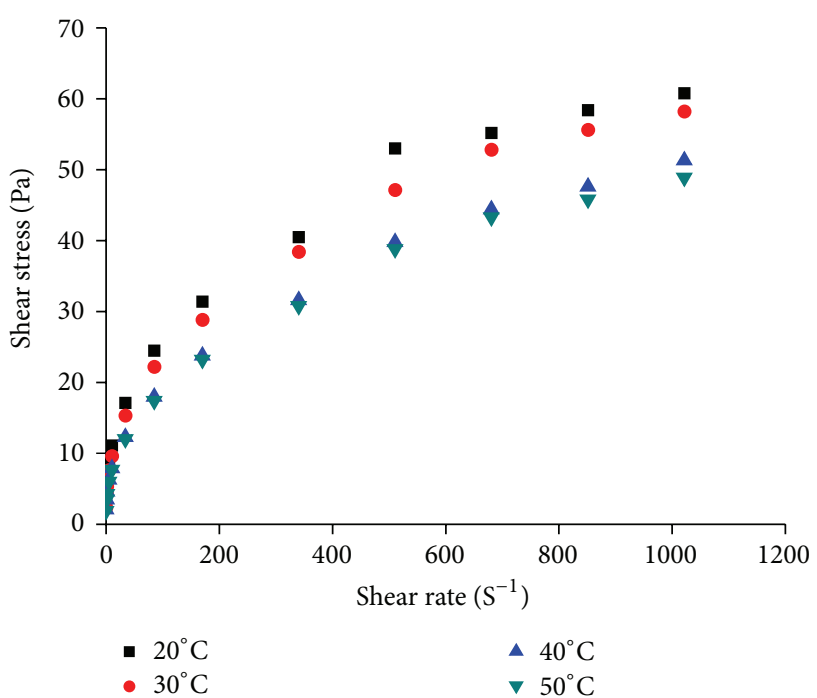

FIGURE 6: Shear stress change under the conditions of different temperatures and different shear rate.

shear rate, the viscosity continues to rise. When drilling fluid begins to flow, due to the low shear rate at the beginning, the separating speed of fluid structure is bigger than its recovery rate, separating degree continues to increase with the increase of shear rate, and viscosity reduces continually with the increase of shear rate. Figure 5 shows the rheology properties under different temperature and the same shear rate. With the rise of temperature, the apparent viscosity has a small decline, but the decline has little impact on performance of drilling fluid.

The shear stress change of drilling fluid under the conditions of different temperatures and different shear rates is shown in Figure 6. On the basis of the two kinds of commonly used rheological models, Bingham and power law, the change of drilling fluid along with temperature and shear rate is evaluated and the results are shown in Table 1. Besides, the appropriate rheological control equation is selected and analyzed.

According to Figure 6, under the same temperature, with the increase of shear rate, shear stress increases continuously, but the increase of shear stress amplitude decreases continuously. Moreover, after the drilling fluid flows, the ratio between shear stress and shear rate is always changing, and the whole process shows no linear segment; initially, shear rate is relatively low, and the separating speed of structure is greater than its recovery rate; with the increases of shear rate, separating degree increases, which is characterized by increasing shear rate and decreasing viscosity; with the increase of structure separating degree, the separating speed decreases, and the change of the shear stress becomes relatively slow. The law effectively expresses the rheological properties of drilling fluid in annulus.

Table 3 shows the comparison of drilling fluid rheology under Bingham mode and power law mode. According to the analysis of the correlation coefficient, the matching degree of rheological formula under the power law mode works better than that of Bingham; the correlation coefficient of power law 
TABLE 3: Applicable formula and correlation coefficient of different drilling fluid rheological models under different temperatures.

\begin{tabular}{lccc}
\hline Model & Temperature $/{ }^{\circ} \mathrm{C}$ & Regression equation & $\begin{array}{c}\text { Correlation } \\
\text { coefficient } \\
R^{2}\end{array}$ \\
\hline \multirow{3}{*}{ Bingham } & 20 & $\tau=0.0576 y+12.382$ & 0.8865 \\
& 30 & $\tau=0.0555 y+10.881$ & 0.9016 \\
& 40 & $\tau=0.0483 y+8.7535$ & 0.9213 \\
\multirow{3}{*}{ Power law } & 50 & $\tau=0.0465 y+8.5448$ & 0.9144 \\
\hline & 20 & $\tau=5.2069 y^{0.3542}$ & 0.9968 \\
& 30 & $\tau=4.3241 y^{0.3710}$ & 0.9982 \\
& 50 & $\tau=3.6477 y^{0.3736}$ & 0.9961 \\
& & $\tau=3.4665 y^{0.3772}$ & 0.9970 \\
\hline
\end{tabular}

mode drilling fluid rheological formula exceeds 0.99 , which can really reflect the flowing law of drilling fluid.

Drilling fluid thixotropy refers to the property of drilling fluid becoming thin after mixing and thickening after placing for a while; in the microlevel, it is the space truss structure of drilling fluid space; under the effect of shear, space truss structure is scattered; after losing shear, particles in drilling fluid contact with each other and bond in a certain geometric relationship; the structure recovery process needs some time to be completed; and the time required to restore structure and the size of the ultimate strength can reflect the strength of the drilling fluid thixotropy. In the engineering research, usually the difference between the final shear and initial shear is used to relatively express the strength of the drilling fluid thixotropy. Cenosphere drilling fluid thixotropy is shown in Figure 7 , in which the shear force is the difference between the final shear and initial shear.

According to Figure 7 cenosphere drilling fluid thixotropy diagram, within the 100 minutes of test time, shear force shows slow increase in the first 20 minutes, quicker increase in the time period of 20-40 min, slow growth in 40-60 min, and little change after $60 \mathrm{~min}$. Conventional thixotropy is expressed by the difference between the final shear and initial shear. The figure shows that there is very small change in the final shear and initial shear during the $10 \mathrm{~min}$, while there is great change later, explaining that the conventional method has certain limitation and cannot really reflect drilling fluid thixotropy. For the drilling fluid with cenosphere, mainly because the polymer adsorbs bridging on solid particle and forms space truss structure, the speed is relatively small; the strength is not very great; the overall thixotropy of the system is relatively good.

From the above analysis, the experiments clearly show drilling fluid has good shear thinning behavior and thixotropy; drilling fluid has good capability of carrying cuttings.

3.2. Dispersion Stability. The experiment uses optical dispersion stability analyzer Turbiscan MA 2000 to analyze optical dispersion of drilling fluid; the principle of optical analyzer is that different fluid has different transmittance and different

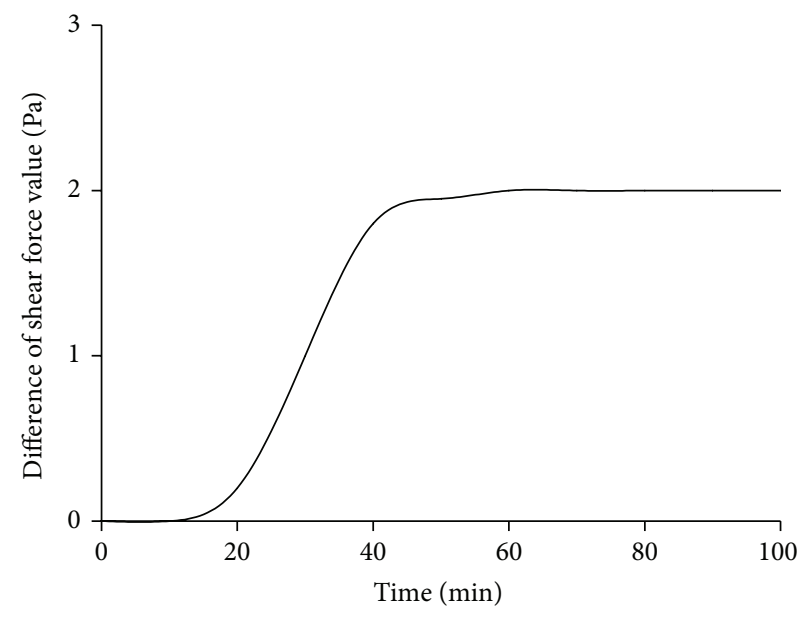

FIGURE 7: Thixotropy analysis of drilling fluid with cenosphere.

reflectance to light $[20,21]$. The same kind of fluid, whose stability changes with time, has different transmittance and reflectance to the light as well.

Experimental steps: laboratory technician took drilling fluid sample into test tube, then took the test tube into the analyzer, and opened Turbiscan Soft to scan; the scanning time was $26 \mathrm{~h}$, and time interval was $2 \mathrm{~h}$. The result is shown in Figure 8.

Figure 8 shows the dispersion stability basically has no change with the increase of time; this also indicates the dispersion stability of drilling fluid is great.

3.3. Sedimentation Stability. Sedimentation stability refers to that if the micron-grade cenosphere is easy to rise in drilling fluid, which is usually measured by rise speed of particle. Experimental steps: let drilling fluid stand for 48 hours in a $500 \mathrm{~mL}$ measuring cylinder, and then measure the density difference between upper and lower section in measuring cylinder. The smaller the density difference is, the better the sedimentation stability is and the more suitable for drilling engineering the drilling fluid is. The research selected drilling fluid with density of $0.86 \mathrm{~g} \cdot \mathrm{cm}^{-3}$ to evaluate sedimentation stability; the result is shown in Table 4.

Table 4 shows that density difference is only $0.01 \mathrm{~g} \cdot \mathrm{cm}^{-3}$ after 48 hours, which means that density difference is in a reasonable range, so the sedimentation stability of drilling fluid is great.

The well length of deep coal-bed methane is usually over $1000 \mathrm{~m}$, which is much longer than the diameter of well. So a plastic tube with a diameter-height ratio of $5.5 \mathrm{~cm}: 185 \mathrm{~cm}$ is used to test the sedimentation stability of drilling fluid in order to guarantee the validity of data. The research also selected drilling fluid with density of $0.86 \mathrm{~g} \cdot \mathrm{cm}^{-3}$ to evaluate sedimentation stability; the result is shown in Table 5.

Table 5 shows that density difference of drilling fluid is small after $144 \mathrm{~h}$, which is still in a reasonable range. Tables 4 and 5 show that drilling fluid can effectively suspend microngrade cenosphere and cuttings, so it could be used as a work fluid. 
TABLE 4: The evaluation of sedimentation stability (method of using measuring cylinder).

\begin{tabular}{lcccc}
\hline Initial density $/ \mathrm{g} \cdot \mathrm{cm}^{-3}$ & Position & Measured density $/ \mathrm{g} \cdot \mathrm{cm}^{-3}$ & Density difference/g. $\mathrm{cm}^{-3}$ & Phenomenon \\
\hline 0.865 & Upper & 0.864 & 0.002 & No obvious change \\
\hline
\end{tabular}

TABLE 5: The evaluation of sedimentation stability (method of using long plastic tube).

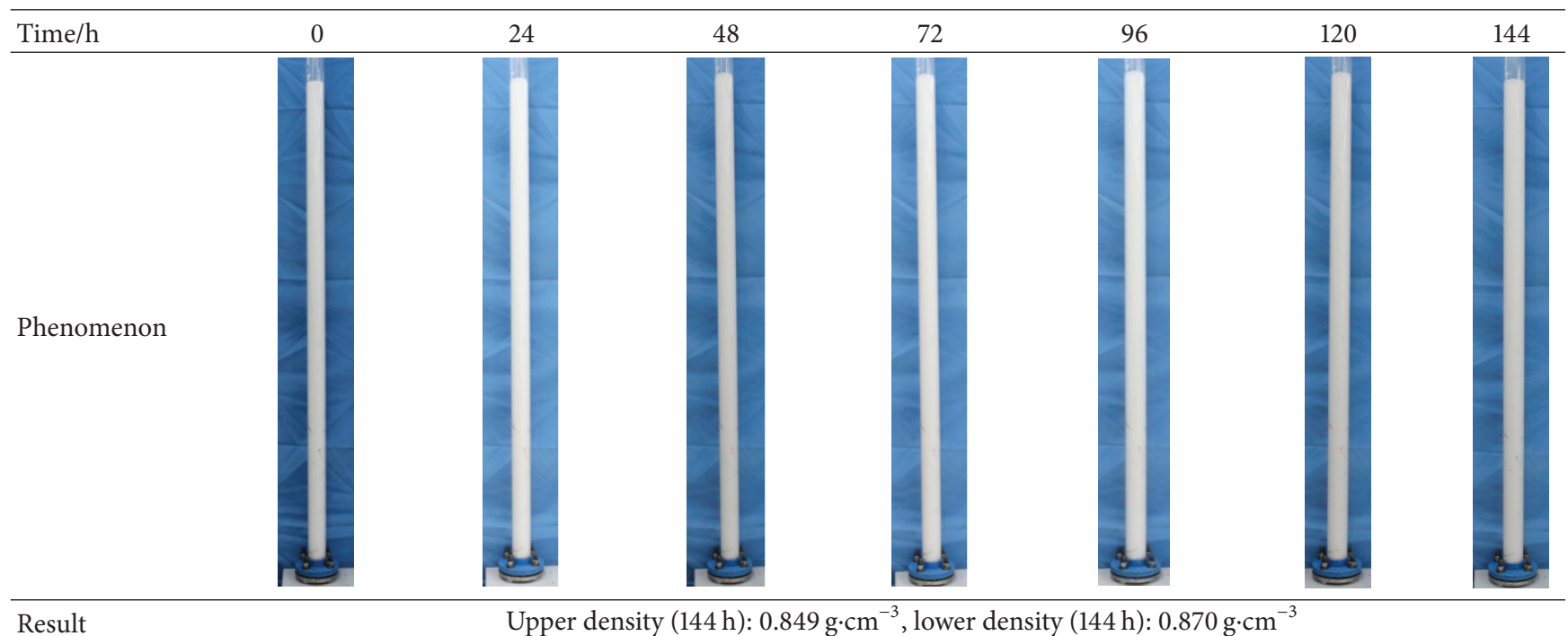
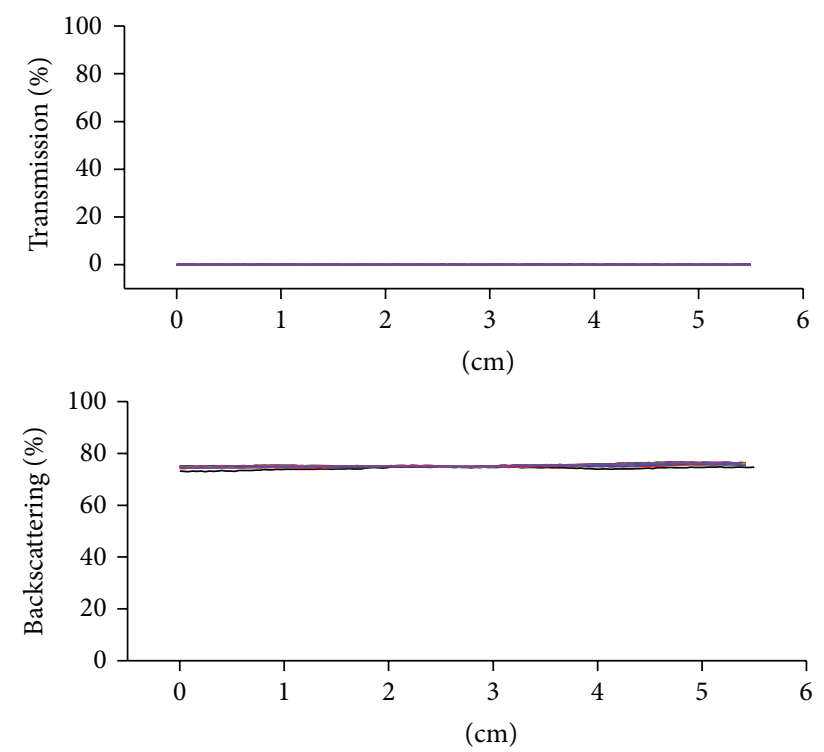

$\begin{array}{ll}-0 & -14 \mathrm{~h} \\ -2 \mathrm{~h} & -16 \mathrm{~h} \\ -4 \mathrm{~h} & -18 \mathrm{~h} \\ -6 \mathrm{~h} & -20 \mathrm{~h} \\ -8 \mathrm{~h} & -22 \mathrm{~h} \\ -10 \mathrm{~h} & -24 \mathrm{~h} \\ -12 \mathrm{~h} & -26 \mathrm{~h}\end{array}$

FIGURE 8: Result of dispersion stability of drilling fluid.

3.4. Particle Size Distribution. Analyzing the particle size distribution of drilling fluid can provide theoretical basis to improve the rheological properties. The ability of reservoir

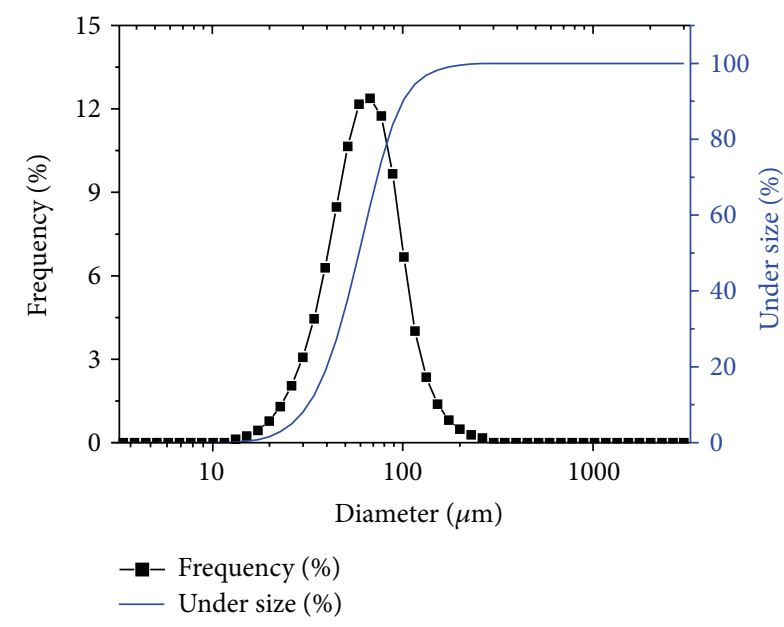

FIGURE 9: Particle size distribution of polymer drilling fluid with micron-grade cenosphere.

protection can be improved by comparatively analyzing the experiment results of particle size distribution of drilling fluid and the size of pores and fractures in CBM.

Test of particle size distribution of drilling fluid was an important means of improving rheological properties and reservoir protection. Particle size determined the filter loss of drilling fluid into the reservoir. The particle size distribution of polymer drilling fluid with micron-grade cenosphere (density is $0.86 \mathrm{~g} \cdot \mathrm{cm}^{-3}$ ) was measured in this research, and the result is shown in Figure 9.

Figure 9 shows the experiment results of particle size distribution of polymer drilling fluid with micron-grade 


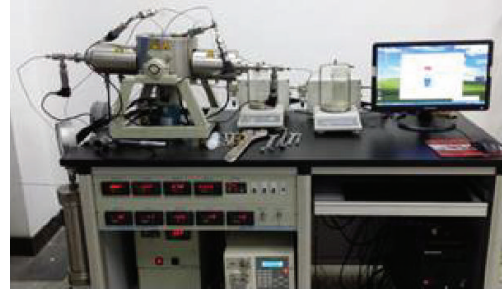

(a)

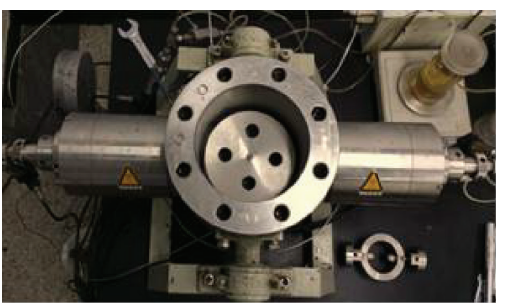

(d)

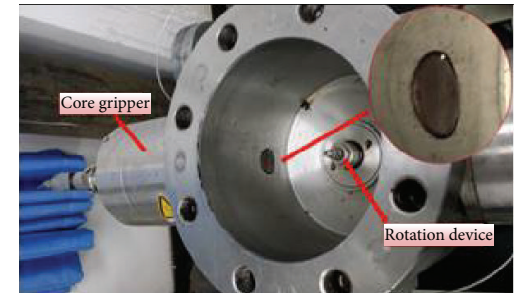

(b)

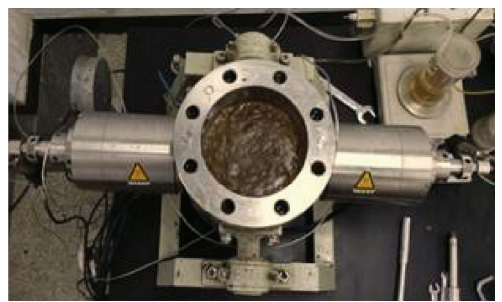

(e)

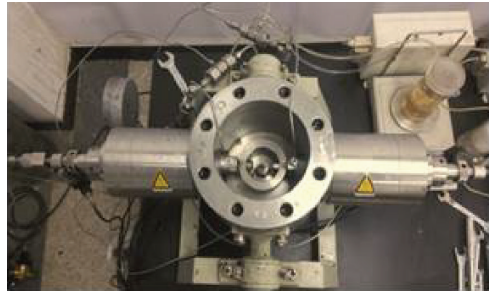

(c)

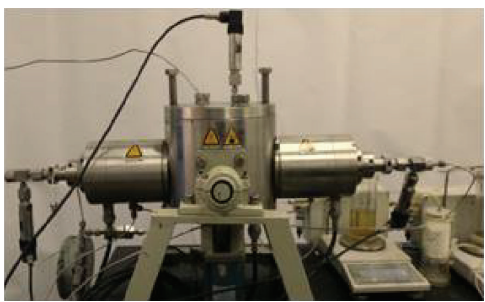

(f)

FIGURE 10: Dynamic damage tester: (a) full view of tester; (b) core in gripper; (c) core displacement process; (d) internal rotation device; (e) joining drilling fluid and rotating (another drilling fluid); (f) sealing and inflating to simulate wellbore conditions.

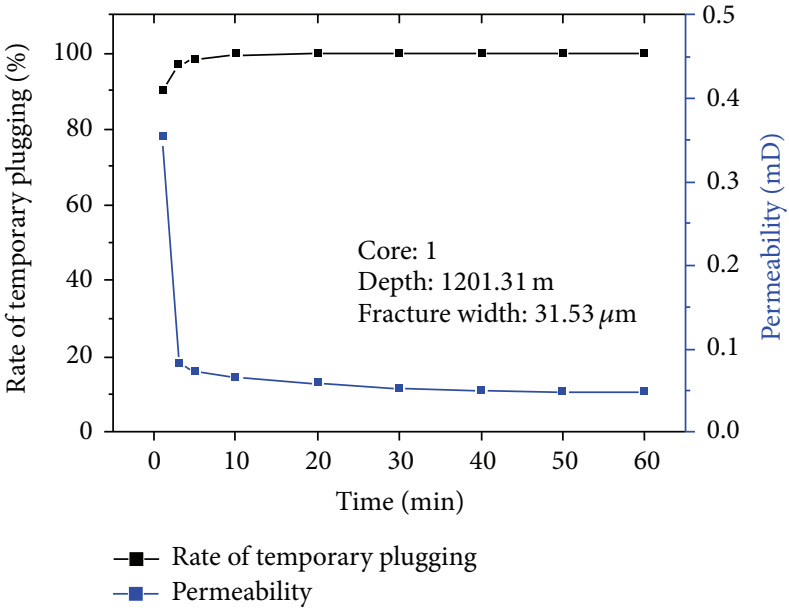

(a)

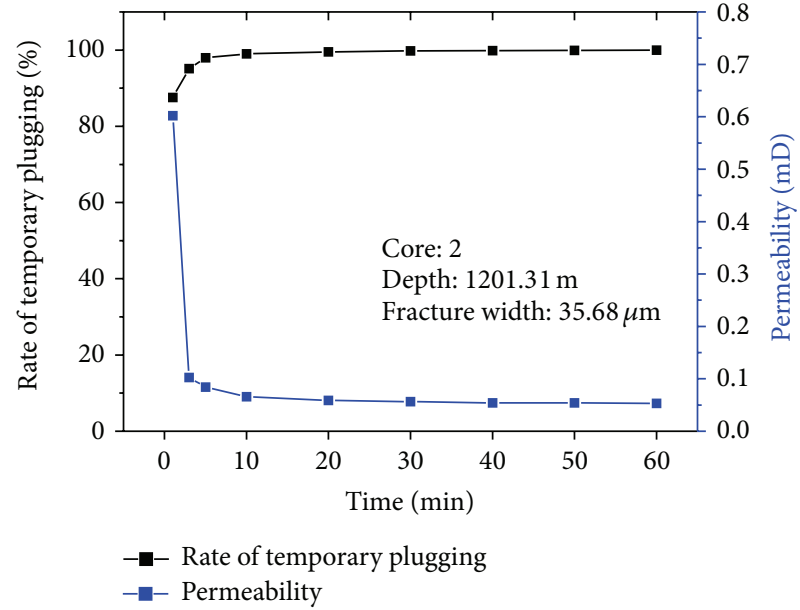

(b)

FIGURE 11: Properties of filter cake of drilling fluid.

cenosphere: median size is $47.6174 \mu \mathrm{m}$, and mean size is $53.7829 \mu \mathrm{m}$. The size of cracks in coal seam is relatively small, so it is not easy for particles in drilling fluid to flow into the reservoir. Large particles and small particles in the drilling fluid form a dense mud cake around the well wall, and the mud cake protects reservoir to suffer less damage of drilling fluid.

3.5. Ability of Reservoir Protection. Production of coal-bed methane is extremely low, which requires that drilling fluid must have a good ability of reservoir protection, so the research selected coal cores from Qinshui Basin to carry out the dynamic damage experiments. Because the permeability of deep coal seam was very small, the experiments used artificial fracture cores.

The experiments evaluated formation time of filter cake, rate of temporary plugging, filter loss, core recovery rate of natural flowback, and so on. Experiments used dynamic damage tester (Figure 10) to simulate downhole conditions; the tester could simulate rotation of drilling string. Experimental temperature was $50^{\circ} \mathrm{C}$, differential pressure was $3.5 \mathrm{MPa}$, shear rate was $150 \mathrm{~S}^{-1}$, damage time was $60 \mathrm{~min}$, and experimental displacement style was forward directionreverse direction-forward direction. The result is shown in Figure 11, Table 6.

Figure 11 shows the properties of filer cake of drilling fluid, drilling fluid forms a tight mud cake at end face of core 
TABLE 6: Results of dynamic damage experiments.

Natural flowback

\begin{tabular}{|c|c|c|c|c|c|c|c|}
\hline Core & $\begin{array}{l}\text { Permeability } \\
\text { measured with } \\
\text { gas } / 10^{-3} \mu \mathrm{m}^{2}\end{array}$ & $\begin{array}{c}\text { Permeability } \\
\text { measured with } \\
\text { water } / 10^{-3} \mu \mathrm{m}^{2}\end{array}$ & Fracture width $/ \mu \mathrm{m}$ & Filter loss $/ \mathrm{mL}$ & $\begin{array}{l}\text { Breakthrough } \\
\text { pressure/MPa }\end{array}$ & $\begin{array}{c}\text { Maximum } \\
\text { recovery rate/\% }\end{array}$ & $\begin{array}{c}\text { Differential } \\
\text { pressure under } \\
\text { maximum } \\
\text { recovery } \\
\text { rate/MPa }\end{array}$ \\
\hline 3 & 96.86 & 0.63 & 28.06 & 0.98 & 2.1 & 93.21 & 2.5 \\
\hline 4 & 147.65 & 1.39 & 34.21 & 1.59 & 1.6 & 88.30 & 2.1 \\
\hline 5 & 213.97 & 2.42 & 39.94 & 2.64 & 0.7 & 83.62 & 1.2 \\
\hline
\end{tabular}

in the first minute. In Figures $11(\mathrm{a})$ and 11(b), rates of temporary plugging are $89.93 \%$ and $87.55 \%$, and permeabilities are $0.3510^{-3} \mu \mathrm{m}^{2}$ and $0.6010^{-3} \mu \mathrm{m}^{2}$, respectively. After 60 minutes, rates of temporary plugging are both close to $100 \%$, permeabilities keep below $0.0610^{-3} \mu \mathrm{m}^{2}$, and the tight mud cake could effectively prevent drilling fluid from flowing into formation, further reducing the damage to reservoir.

Table 6 shows that the effect of reservoir protection of polymer drilling fluid with micron-grade cenosphere is good, and recovery rate of natural flowback can reach more than $80 \%$. Under the condition of fractures, with the increase of fracture fluid permeability, the fracture width increases; the drilling fluid filtration loss rises rapidly; the breakthrough pressure of natural flowback mud cake continues to decrease. The reason is that the process of blockage within fractures needs to build a mesh structure and seal reticular formation pore; when fracture width increases, the matching degree of the temporary plugging particles in drilling fluid, fiber, and other reservoir protection agents with the fractures decreases; the ability of drilling fluid in building mesh structure abates; temporary plugging pore ability and the stability after the temporary plugging weaken. As a result, fracture pressure reduces and the filtration loss increases.

\section{Conclusions}

Comparing advantages and disadvantages of conventional drilling fluid of CBM wells, the research optimized the best agents of drilling fluid, which included micron-grade cenosphere, tackifier, waterproof lock agent, corrosion inhibitor, antifoaming agent, carbonate, and fiber, and these all formed polymer drilling fluid with micron-grade cenosphere. Then the study evaluated the performances of rheological properties, stability, and reservoir protection. Based on the results of this research, the following conclusions can be drawn: (1) the drilling fluid has good rheological properties, good density adjustability, and low filter loss; (2) rheological properties of drilling fluid have a tiny change under different temperature or different shear rate; (3) dispersion stability basically has no change with the increase of time during $26 \mathrm{~h}$; (4) two methods were used to evaluate sedimentation stability, and the results of the methods show drilling fluid can effectively suspend micron-grade cenosphere and cuttings; (5) drilling fluid has good performance to protect reservoir, and recovery rate could reach more than $80 \%$.

\section{Conflict of Interests}

The authors declare that there is no conflict of interests regarding the publication of this paper.

\section{Acknowledgment}

The authors would like to acknowledge the financial support of the National Science and Technology Major Project of China (Grant no. 2011ZX05042-002-001).

\section{References}

[1] Z. Shouren, "Proposed effective developing method for the deep coalbed methane," China Coalbed Methane, vol. 4, pp. 18-21, 2011.

[2] J. He, X. Wu, Y. Xiang, Y. Yi, and J. Ma, "Laboratory core flow research on enzyme biodegradable drilling fluid used for coal bed methane," Drilling Fluid and Completion Fluid, vol. 30, no. 2, pp. 33-36, 2013.

[3] M. L. Stanley, US Patent No. 5,411,104, US Patent and Trademark Office, Washington, DC, USA, 1995.

[4] Y. Jianping, S. Baosheng, and Z. Chuncai, "Coal reservoir permeability and its controlled factors in China," Journal of China Coal Society, vol. 24, no. 2, pp. 118-122, 1999.

[5] K. L. Barr, "A guideline to optimize drilling fluids for coalbed methane reservoirs," in Proceedings of the SPE Rocky Mountain Petroleum Technology Conference, Society of Petroleum Engineers, Denver, Colo, USA, April 2009.

[6] A. G. Lscan, M. V. Kok, and H. Strauss, "Evaluation of formation damage of Turkish southeastern reservoirs caused by drilling fluids," in Proceedings of the SPE/IADC Middle East Drilling Technology Conference and Exhibition: Innovating to Meet Challenges, pp. 111-116, Cairo, Egypt, October 2007.

[7] N. Maricic, S. D. Mohaghegh, and E. Artun, "A parametric study on the benefits of drilling horizontal and multilateral wells in coalbed methane reservoirs," SPE Reservoir Evaluation \& Engineering, vol. 11, no. 6, 2008.

[8] L.-H. Zheng, S.-Z. Meng, Y. Cao, and Z.-F. Li, "Laboratory studies on control coal bed methane formation damage by Fuzzy-Ball based drilling fluids," Journal of the China Coal Society, vol. 35, no. 3, pp. 439-442, 2010.

[9] T. Gentzis, N. Deisman, and R. J. Chalaturnyk, "Effect of drilling fluids on coal permeability: impact on horizontal wellbore stability," International Journal of Coal Geology, vol. 78, no. 3, pp. 177-191, 2009. 
[10] L. V. Baltoiu, B. K. Warren, and T. A. Natras, "State-of-the-art in coalbed methane drilling fluids," SPE Drilling \& Completion, vol. 23, no. 3, pp. 250-257, 2008.

[11] Q.-S. Yue, L.-F. Zou, G.-Z. Jiang et al., "Laboratory research on degradable drilling fluid for pinnate horizontal well based on coalbed methane," Journal of the China Coal Society, vol. 35, no. 10, pp. 1692-1695, 2010.

[12] Z. Lihui, "Application state and prospects of bionic fuzzy-ball drilling fluids for coalbed methane drilling," Oil Drilling \& Production Technology, vol. 33, no. 3, pp. 78-81, 2011.

[13] G. H. Medley Jr., W. C. Maurer, and A. Y. Garkasi, "Use of hollow glass spheres for underbalanced drilling fluids," in Proceedings of the SPE Annual Technical Conference and Exhibition, Society of Petroleum Engineers, Dallas, Tex, USA, October 1995.

[14] G. H. Medley Jr., J. E. Haston, R. L. Montgomery, I. D. Martindale, and J. R. Duda, "Field application of lightweight hollow glass sphere drilling fluid," in Proceedings of the SPE Annual Technical Conference and Exhibition, Society of Petroleum Engineers, San Antonio, Tex, USA, October 1997.

[15] M. J. Arco, J. G. Blanco, R. L. Marquez et al., "Field application of glass bubbles as a density-reducing agent," in Proceedings of the SPE Annual Technical Conference and Exhibition, Drilling and Completion, pp. 115-126, Society of Petroleum Engineers, Dallas, Tex, USA, October 2000.

[16] J. Blanco, F. Ramirez, F. Mata, A. Ojeda, and B. Atencio, "Field application of glass bubbles as a density reducing agent in an oil base drilling fluid for marginal/low-permeability/lowpressure reservoirs," in Proceedings of the SPE Gas Technology Symposium, Society of Petroleum Engineers, Calgary, Canada, April-May 2002.

[17] X. M. Jia, X. R. Feng, L. P. Yang, and H. A. Zhou, "Field application of hollow glass microsphere low density drilling fluid," Drilling Fluid \& Completion Fluid, vol. 24, supplement, pp. 98100, 2007.

[18] X. S. Yu, "Application of low density and solid-free glass bead drilling fluid in DP3 well," Exploration Engineering (Rock \& Soil Drilling and Tunneling), vol. 35, no. 10, pp. 14-16, 2008.

[19] S. L. Chen, "Applications of hollow glass bubbles in underbalanced drilling on well shen-289," Petroleum Drilling Techniques, vol. 38, no. 1, pp. 60-62, 2010.

[20] S. Lionti-Addad and J.-M. Di Meglio, "Stabilization of aqueous foam by hydrosoluble polymers. 1. Sodium dodecyl sulfatepoly(ethylene oxide) system," Langmuir, vol. 8, no. 1, pp. 324327, 1992.

[21] J. F. Argillier, S. Saintpere, B. Herzhaft, and A. Toure, "Stability and flowing properties of aqueous foams for underbalanced drilling," in Proceedings of the SPE Annual Technical Conference and Exhibition, Society of Petroleum Engineers, New Orleans, La, USA, September 1998. 

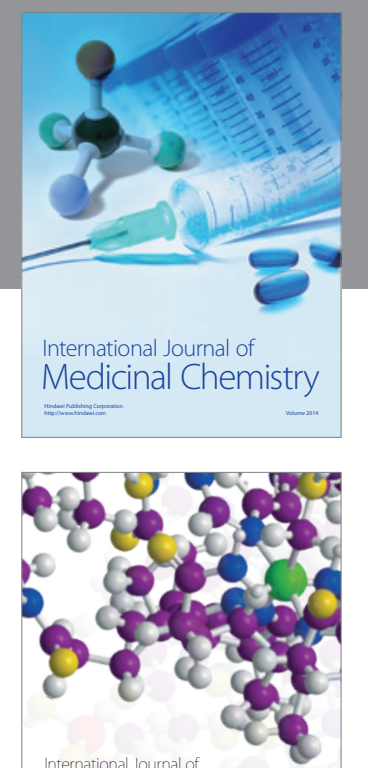

\section{Carbohydrate} Chemistry

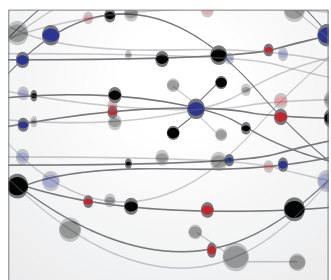

The Scientific World Journal
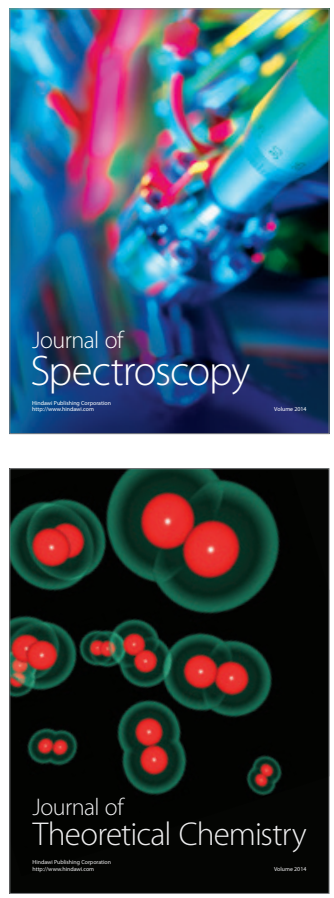
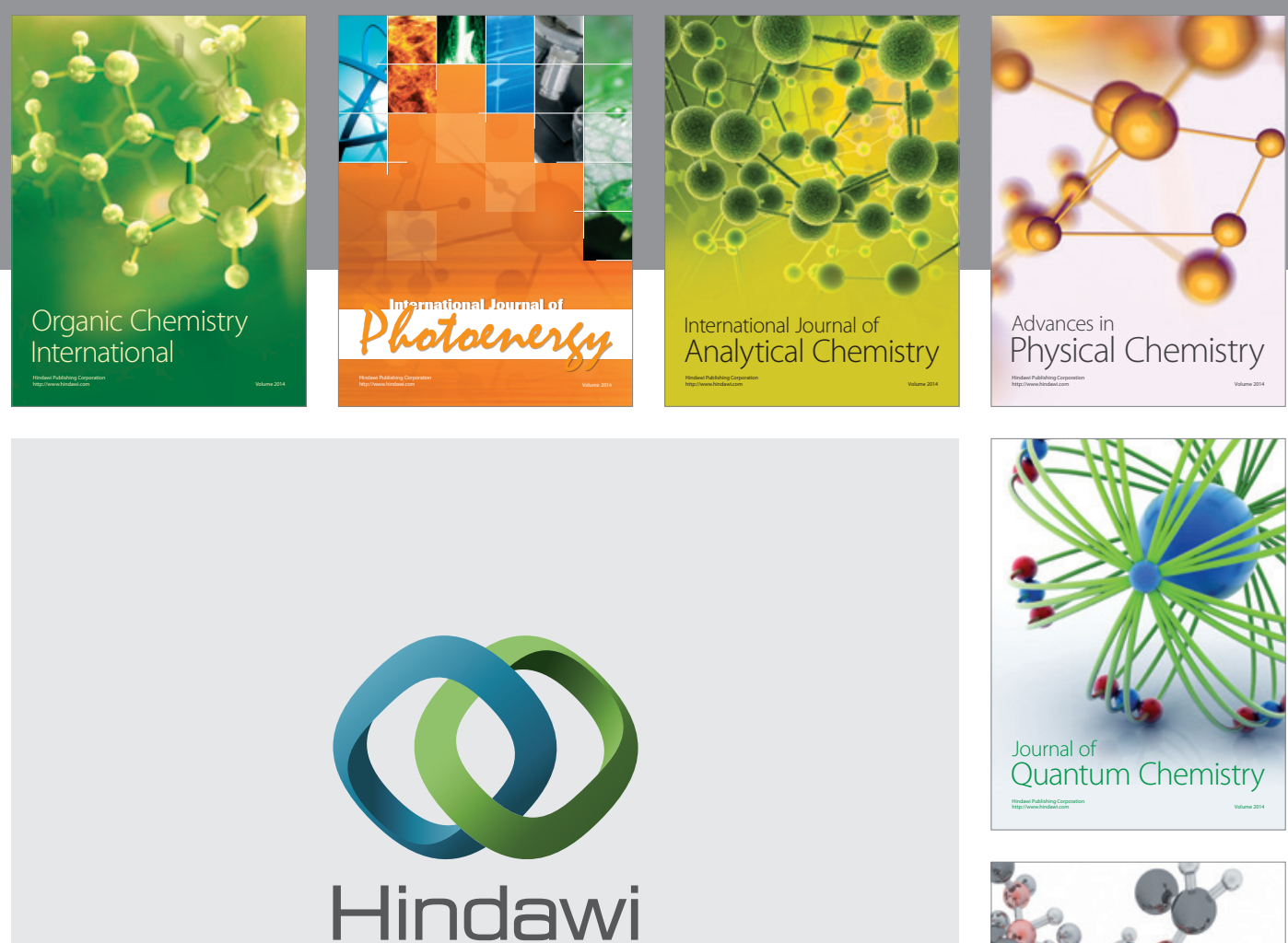

Submit your manuscripts at

http://www.hindawi.com

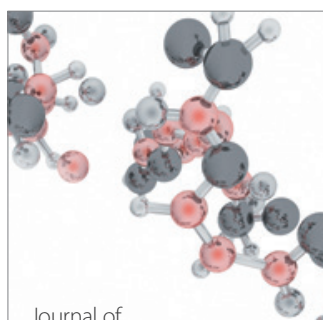

Analytical Methods

in Chemistry

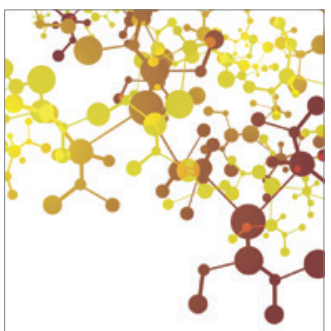

Journal of

Applied Chemistry

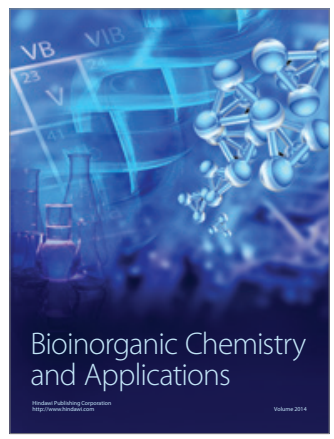

Inorganic Chemistry
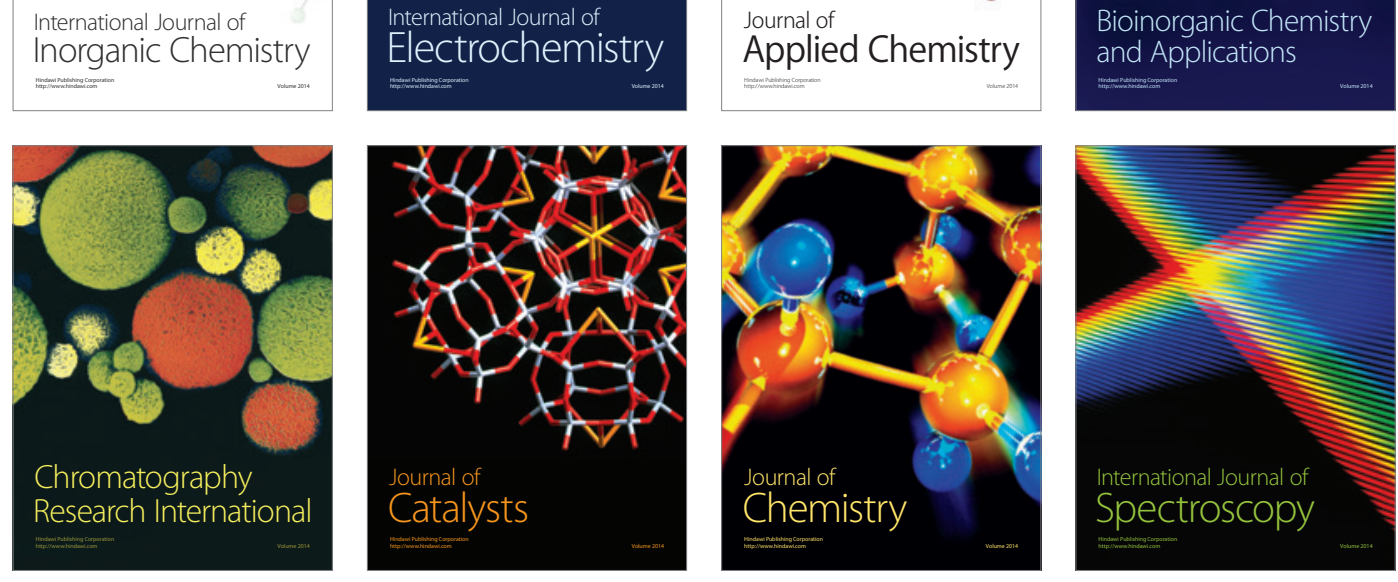